Economics, Business and Management Science Journal, 1(1) 2021: 40-46

DOI: https://doi.org/10.34007/ebmsi.v1i1.11

Economics, Business and Management Science Journal

Available online: https://journal.mahesacenter.org/index.php/ebmsj

\title{
Strategi Usaha Menengah Kecil dan Mikro Bertahan di Era Pandemi-19
}

\section{Strategy for Small and Medium Enterprises to Survive the Pandemic-19 Era}

\author{
Hadion Wijoyo ${ }^{1)}$ \& Irfan Rizka Akbar ${ }^{2)}$ \\ 1) Sekolah Tinggi Manajemen Informatika Komputer Dharmapala Riau, Indonesia \\ 2) Universitas Pamulang, Indonesia
}

\begin{abstract}
Abstrak
Usaha Menengah Kecil dan Mikro (UMKM) merupakan salah satu usaha yang sangat menopang aktivitas ekonomi apalagi dalam kondisi krisis ekonomi dunia akibat pandemi covid-19. Peningkatan UMKM menunjukkan bagaimana sektor ini masih menjadi andalan bagi perekonomian masyarakat. Perputaran ekonomi dengan jelas terlihat di sektor ini. Hal ini sejalan dengan informasi yang disampaikan oleh Dirjen Industri Kecil dan Menengah Kementerian Perindustrian Euis Saedah bahwa prospek bisnis usaha kecil masih sangat bagus, mengingat jumlah penduduk di Indonesia sangat besar, sekitar 250 juta jiwa. Penelitian ini menggunakan metode studi kepustakaan, dimana Studi kepustakan adalah segala usaha yang dilakukan oleh peneliti untuk menghimpun informasi yang relevan dengan topik atau masalah yang akan atau sedang diteliti. Email marketing adalah cara yang paling efektif untuk membangun koneksi dengan calon pelanggan dan mengarahkan mereka menjadi pelanggan setia. Email marketing juga cara yang bersifat personal untuk berkomunikasi dengan pelanggan.
\end{abstract}

Kata Kunci: Strategi; Usaha Menengah Kecil Dan Mikro; Era Pandemi-19

\section{Abstract}

Small and Medium Enterprises (MSMEs) are one of the businesses that really support economic activity, especially in conditions of the world economic crisis due to the Covid-19 pandemic. The increase in MSMEs shows how this sector is still a mainstay for the people's economy. The economic turnover is clearly visible in this sector. This is in line with the information conveyed by the Director General of Small and Medium Industry of the Ministry of Industry Euis Saedah that the prospects for small business businesses are still very good, given the very large population in Indonesia, around 250 million people. This research uses the literature study method, where the librarian study is all the efforts made by the researcher to gather information that is relevant to the topic or problem to be or is being researched. Email marketing is the most effective way to build connections with potential customers and turn them into loyal customers. Email marketing is also a personal way to communicate with customers.

Keywords: Strategy; Small and Micro Medium Enterprises; Pandemic Era-19

How to Cite: Wijoyo, H., \& Akbar, I.R., (2021). Strategi Usaha Menengah Kecil Dan Mikro Bertahan Di Era Pandemi-19. Economics, Business and Management Science Journal, 1(1): 40-46,

*E-mail: Hadion.wijoyo@lecturer.stmikdharmapalariau.ac.id
**E-mail: dosen02461@unpam.ac.id

ISSN: 2775-3794 (Online) 


\section{PENDAHULUAN}

Pandemi Covid-19 membuat semua lini usaha (perekonomian) terganggu (resesi), pemerintah menyadari bahwa hanya Usaha Mikro, Kecil, dan Menengah yang bisa menopang atau memperlambat turunya tingkat pertumbuhan perekonomian Bangsa. Namun satu sisi pengelolaan UMKM yang masih banyak menggunakan pola sederhana (tradisional) menyebabkan tingkat pertumbuhan UMKM belum bisa memberikan kontribusi besar dalam perekonomian karena belum bisa mengimbangi lajunya tingkat petumbuhan digital.

Dewasa ini Usaha Menengah Kecil dan Mikro (UMKM) merupakan salah satu usaha yang sangat menopang aktivitas ekonomi apalagi dalam kondisi krisis ekonomi dunia akibat pandemi covid-19. Peningkatan UMKM menunjukkan bagaimana sektor ini masih menjadi andalan bagi perekonomian masyarakat. Perputaran ekonomi dengan jelas terlihat di sektor ini. Hal ini sejalan dengan informasi yang disampaikan oleh Dirjen Industri Kecil dan Menengah Kementerian Perindustrian Euis Saedah bahwa prospek bisnis usaha kecil masih sangat bagus, mengingat jumlah penduduk di Indonesia sangat besar, sekitar 250 juta jiwa. Namun demikian, pelaku usaha di sektor makanan ringan, sedang bersaing ketat dengan sesame pelaku usaha lokal maupun dengan produk impor, baik itu legal maupun ilegal, dari China, Malaysia, Thailand, atau Jepang (Sulistyandari et al., 2017).

Strategi pemasaran yaitu suatu konsep perencanaan komunikasi pemasaran terpadu yang mengevaluasi peran strategis dari berbagai disiplin komunikasi, misalnya periklanan umum, penjualan personal, pemasaran langsung, hubungan masyarakat, dan menggabungkan beberapa disiplin ini untuk memberikan kejelasan, konsistensi, dan pengaruh komunikasi yang maksimum melalui integrasi yang menyeluruh (Philip Kotler dan Gary Amstrong. 2007).

Pengertian strategi digital marketing yaitu konsep strategi pemasaran terpadu dengan menggunakan digital untuk mempromosikan produk atau jasa dengan memanfaatkan media digital berupa internet atau pemasaran online untuk memperluas jangkauan konsumen (https://markey.id/blog/marketing/pemasaran-digital).
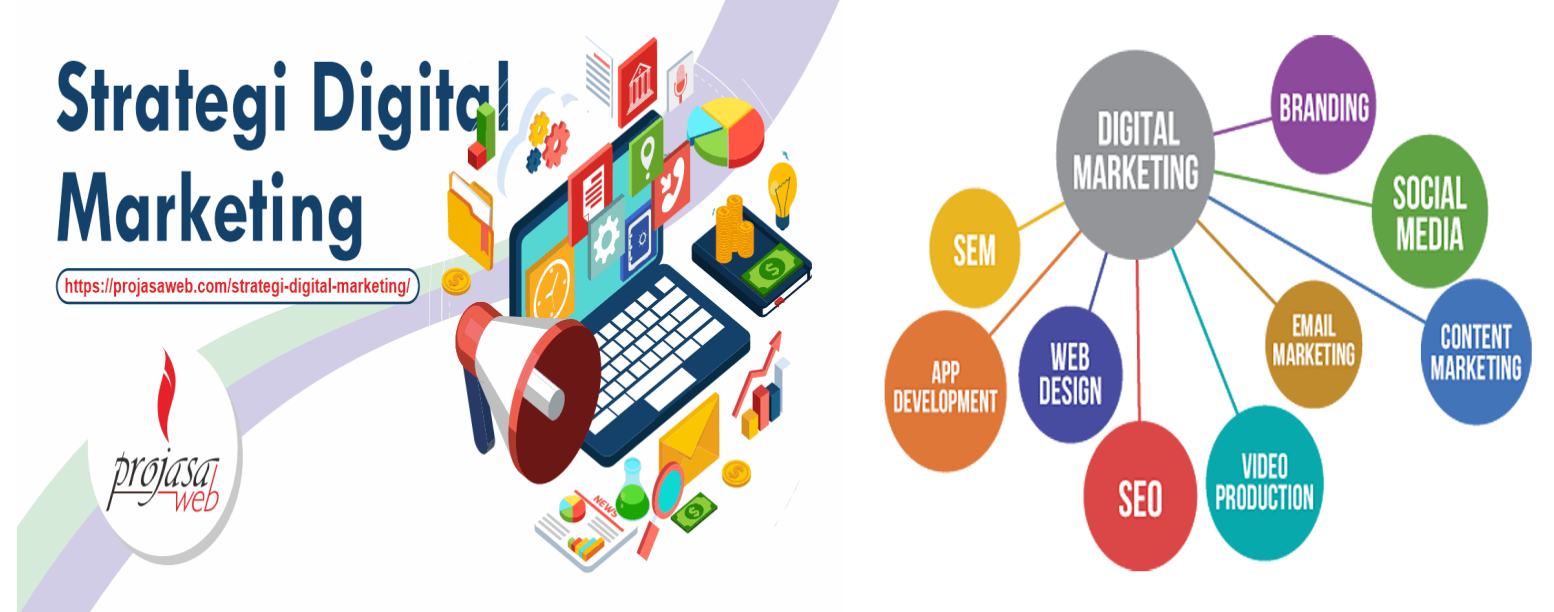

Sumber: https://www.bing.com (download, Juli 2020).

Era revolusi industry 4.0 dan society 5.0 strategi pemasaran digital sangat berperan dalam membangun jaringan, komunikasi dengan konsumen dan memperkenalkan produk atau jasa sebuah perusahaan. Adapaun media digital yang umum diakses dalam mengimplementasikan strategi pemasaran digital yaitu website, blog dan juga sosial media (Facebook, Instagram, Whatsapp, Line, dsb), SEO, SEM, Email Marketing, Content Marketing, branding dan App Development.

Salah satu hal yang menjadi penentu bersaingnya suatu produk adalah teknik pemasarannya. Pemasaran yang efektif dan kreatif akan menjangkau lebih banyak konsumen. Pemasaran adalah salah satu kegiatan pokok yang perlu dilakukan oleh perusahaan baik itu perusahaan barang atau jasa dalam upaya untuk mempertahankan kelangsungan hidup usahanya. Hal tersebut disebabkan karena pemasaran merupakan salah satu kegiatan perusahaan, dimana 象https://mahesacenter.org/

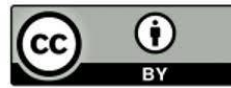


secara langsung berhubungan dengan konsumen. Maka kegiatan pemasaran dapat diartikan sebagai kegiatan manusia yang berlangsung dalam kaitannya dengan pasar (Wijoyo, Sunarsi, et al., 2020). Efek globalisasi juga di rasakan oleh sektor UMKM. UMKM yang tidak bisa beradaptasi dengan globalisasi makan perlahan akan kehilangan daya saingnya. Proses globalisasi dipengaruhi oleh banyak faktor, diantaranya; teknologi internet, infrastruktur telekomunikasi dan transportasi, pertukaran pelajar, dan lain-lain. Pada umumnya globalisasi berhubungan dengan perubahan menyeluruh pada bidang ekonomi, industri, gaya hidup, dan aspek-aspek kehidupan lainnya (Wijoyo, Sunarsi, et al., 2020).

Sebagai contoh salah satu UMKM yakni Kerupuk Rasa Jengkol Dong Dong Snack adalah UMKM yang mulai beroperasi sekitat tiga tahun lalu dengan mengolah Jengkol sebagai bahan utama menjadi kerupuk rasa jengkol yang di pasarkan secara manual dengan sistem titip dari satu tempat ke tempat lainnya. Hal ini menyebabkan harus adanya pembagian hari produksi, memotong, menjemur, menggoreng, membungkus dan memasarkan. Karena di kerjakan oleh tiga orang maka proses pengolahan bahan baku sampai barang jadi memerlukan waktu yang tidak sedikit serta di tambahkan dengan waktu memasarkannya, akibatnya dalam waktu sebulan jumlah produksi dengan permintaan tidak seimbang. Para wirausaha ini kewalahan dalam pemasaran produknya, hal ini dikarenakan luasnya wilayah pemasaran di Kota Pekanbaru. Seorang wirausaha berperan baik secara internal maupun eksternal. Secara internal seorang wirausaha berperan dalam mengurangi tingkat kebergantungan terhadap orang lain, meningkatkan kepercayaan diri, serta meningkatkan daya beli pelakunya. Secara eksternal, seorang wirausaha berperan dalam menyediakan lapangan kerja bagi para pencari kerja (Wijoyo, Indrawan, et al., 2020). Hasil penelitian disektor makanan (Rumah Makan) menunjukkan bahwa terjadi peningkatan penjualan ketika rumah makan dikelola dengan menggunakan teknologi secara online daripada manual (Wijoyo, 2019).

Adapun tujuan dari penelitiain ini adalah untuk memberikan sumbangan pemikiran bagi semua stakeholders dalam mengelola UMKM di Era digital.

\section{METODE PENELITIAN}

Dalam Penelitian ini menggunakan metode studi kepustakaan, dimana Studi kepustakan adalah segala usaha yang dilakukan oleh peneliti untuk menghimpun informasi yang relevan dengan topik atau masalah yang akan atau sedang diteliti. Informasi itu dapat diperoleh dari bukubuku ilmiah, laporan penelitian, karangan-karangan ilmiah, tesis dan disertasi, peraturanperaturan, ketetapan-ketetapan, buku tahunan, ensiklopedia dan sumber-sumber tertulis baik tercetak maupun elektronik lain.

\section{HASIL DAN PEMBAHASAN}

Beberapa Langkah yang harus dipahami sebelum memulai pemasaran digital, yaitu

1. Fokus dan komprehensif Perhatikan Bisnis, Implementasi digital marketing yang berhasil terjadi dengan perbaikan manajemen pada setiap aspek bisnis.

2. Kepuasan Layanan Pelanggan, Ulas interaksi dengan pelanggan di website dan sosial media, baik melalui komentar, email ataupun panggilan telepon. Walaupun bisnis atau merek sudah terkenal, pastikan layanan untuk konsumen yang terbaik dan memuaskan. Dengan demikian proses digital marketing hingga ke transaksi akan terlaksana dengan lancar.

3. Monitoring Penjualan dan Pemasaran, Penjulan harus memenuhi permintaan konsumen dimanapun konsumen berada, baik itu permintaan secara online maupun offline.

4. Pahami Konsumen, Untuk memasarkan bisnis secara efektif, tugas terpenting memahami konsumen yang membutuhkan produk atau jasa yang ditawakan dan mendorong konsumen untuk membuat keputusan pembelian.

5. Target capaian usaha, Membuat bisnis plan dan manajemen usaha yang terukur. Capaian usaha yang konkrit akan mepermudah menjalankan strategi pemasaran digital.

6. Kemampuan Sumber Daya, Kemampuan sumberdaya untuk memberikan pelayanan terbaik, ketersediaan produ dan pendistribusian produk hingga konsumen akhir harus dimiliki oleh setiap pemasar.

fww https://mahesacenter.org/ 
7. Edukasi Diri Sendiri, Pembelajaran untuk menambah pengetahuan terkait pemasaran digital menjadi dasara utama bagi pemasar. Analisa strategi pemasaran digital membawa pembisni mengambil keputusan strategi untuk menentukan platform pemasaran digital yang tepat untuk memulai memasarkan produk dan jasa kepasar konsumen.

Selanjutnya bagaimana cara memulai digital marketing bagi pelaku usaha yang saat ini sudah, sedang, atau bahkan yang baru mengendaki langkah pemasaran dengan menggunakan sarana teknologi digital. Untuk memulai pemasaran digital diawali dengan: pembuatan company profile yang kemudian dipajang di situs website; Persiapan pemanfaatan ragam sosial media/internet; Menyiapkan Sarana dan Prasarana marketing digital (situs-website, akun sosial media, artikel untuk diunggah pada blog, materi produk/jasa); Menyiapkan konten dengan isi konten yang menarik perhatian dan shareable; Lakukan Evaluasi dan feedback setiap konten yang telah diunggah di situs website, atau media sosial media; Join Public Marketplace, bergabung dalam komunitas marketplace untuk membangun jaringan dan citra merek.

Implementasi pemasaran digital melalui:

1. Pasarkan Produk Melalui Media Sosial, Peningkatan penjualan produk dengan pemasaran digital dilakukan adalah membuat akun media sosial untuk brand Anda, seperti akun Facebook, Instagram, Twitter, dan sebagainya. Semua informasi visual, audio, foto, komentar, dan artikel tentang bisnis diposting yang menarik dengan menggunakan model yang sesuai dengan produk atau jasa perusahaan. Setiap postingan di media social harus di sertaka caption yang menarik dan persuasif untuk menyampaikan pesan promosi.

2. Manfaatkan Platform Website, Untuk Memperluas Audiens Produk dan jasa, Website sebagai platform digital dinilai sebagai media pemasaran yang baik dalam jangka waktu panjang. Meskipun berbagai forum online hadir sebagai media promosi, website tetap memiliki segmen yang luas. Penggunaan website untuk memperkenalkan produk dan jasa membuat pembeli semakin percaya karena brand memiliki situs yang meyakinkan..

3. Kirim Email Marketing Kepada Segmen Pasar, Strategi menjalankan pemasaran digital yang cukup ampuh salah satunya adalah email marketing. Karena melalui media promosi ini, email marketing dinilai sebagai sarana pemasaran yang efektif dan tertarget. Seputar info tentang produk baru atau promo, dan info lain terkait bisnis. Email marketing upaya untuk melakukan pendekatan dan menciptakan hubungan personal dengan pelanggan maupun calon pembeli.

4. Menawarkan Audiens Sebagai Reseller Produk, Penjualan produk atau jasa menggunakan pemasaran digital bisa diterapkan menggunakan sistem reseller. System seller dapat meningkatkan penjualan produk karena jangkauan pasar yang lebih luas dan penjualan dalam jumlah besar. Meskipun harga yang tetapkan untuk reseller jauh lebih murah.

5. Informasikan Review Produk dan Testimoni Pelanggan Kepada Calon Pembeli, Evaluasi yang rutin sangat diperlukan untuk menjalankan pemasaran digital. Pada kontek ini perlu ada psoting terkait testimoni serta review produk dari pelanggan. Cara ini dinilai sangat efektif dalam membangun kepercayaan calon pembeli terhadap produk dan dapat memberikan pelayanan terbaik untuk pelanggan.poinformasi tersebut akan menciptakan engagement serta membuat pembeli merasa puas dengan produk atau jasa yang dibeli konsumen (Musnaini et al., 2020).

berikut:

Ada beberapa Langkah yang digunakan dalam Teknik Search engine Optimization, sebagai

1. Install Plugin Yoast SEO, Memasang plugin Yoast SEO adalah langkah bijak untuk memulai rangkaian optimasi SEO yang panjang. Yoast SEO menyediakan berbagai fitur untuk meningkatkan kualitas SEO website. Beberapa fitur utama Yoast SEO adalah mengubah title tag dan meta description, submit XML Sitemap, mengubah permalink, verifikasi Google Webmaster Tools, dan menganalisis konten. Analisis konten adalah fitur paling menarik dari Yoast SEO. Fitur ini akan mengingatkan jika ada konten belum sesuai dengan kaidah SEO yang benar.

2. Tambahkan Website di Google Search Console, Google Search Console (sebelumnya dikenal sebagai Google Webmaster Tools) adalah platform gratis bagi para pemilik website untuk 色hths://mahesacenter.org/

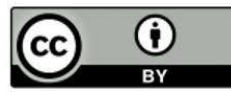


memonitor bagaimana kinerja website di ranah organik Google. Google Search Console memungkinkan untuk mengetahui domain yang memberikan link ke website (referring domain), kinerja website di perangkat mobile, hingga analisis halaman website dengan trafik tertinggi.

3. Buat Sitemap, Sitemap adalah daftar berisi semua halaman website yang dapat diakses oleh pengunjung dan mesin pencari. Dengan adanya sitemap, website akan lebih mudah ditemukan oleh mesin pencari dan lebih cepat terindeks. Sitemap juga akan memberitahu mesin pencari ketika terjadi perubahan struktur di website. Membuat sitemap termasuk teknik SEO dasar namun sangat penting peranannya.

4. Pasang Google Analytics, Selain memasang Google Search Console, perlu memasang Google Analytics. Google Search Console dan Google Analytics memiliki fungsi yang berbeda. Fungsi utama Google Search Console adalah untuk memeriksa performa website di hasil pencarian, sedangkan fungsi utama Google Analytics adalah untuk mengidentifikasi perilaku pengunjung website.

5. Tingkatkan Kecepatan Website, Salah satu hal yang paling dibenci oleh para pengunjung website adalah loading lambat. Loading website yang lama membuat pengunjung website jengkel dan akhirnya mencari website lain yang bisa memberikan informasi lebih cepat. Sebagus apa pun konten yang dibuat, pengunjung website tidak mempunyai toleransi untuk loading lambat.

6. Riset Keyword, Tidak melakukan riset keyword sebelum membuat konten adalah kesalahan fatal bagi pemilik website dan blog. Riset keyword akan membantu untuk menemukan kata kunci yang relevan bagi pembaca. Ada lima indikator riset keyword yang perlu diperhatikan, yaitu volume pencarian, tingkat kesulitan keyword, saran kata kunci, SERP, dan search inten.

7. Targetkan Long Tail Keyword, Terdapat dua jenis kata kunci berdasarkan jumlah kata di dalamnya, yaitu short tail keyword dan long tail keyword. Short tail keyword adalah kata kunci yang terdiri dari satu atau dua kata seperti "membuat blog" dan "membuat website". Di sisi lain, long tail keyword adalah kata kunci yang terdiri dari tiga kata atau lebih seperti "cara membuat blog dengan WordPress" dan "cara membuat blog dengan Blogger". Volume pencarian long tail keyword cenderung lebih kecil dibandingkan short tail keyword. Namun, long tail keyword lebih efektif untuk mendatangkan trafik. Menurut Neil Patel, long tail keyword

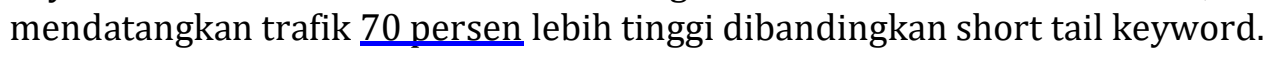

8. Buat Konten yang Lengkap dan Menarik, Ketika orang mencari sebuah kata kunci di mesin pencari, mereka menginginkan jawaban yang lengkap sehingga bisa menyelesaikan masalah yang mereka hadapi. Google pun menyadari kebutuhan penggunanya dan mulai mengutamakan konten-konten yang lengkap untuk menduduki posisi teratas di hasil pencarian. Penambahan gambar ilustrasi, infografik, atau video untuk melengkapi artikel. Media visual akan membantu pembaca untuk memahami isi artikel dengan mudah. Jika mereka puas dengan konten lengkap , bukan tidak mungkin mereka akan membagikan konten tersebut di media sosial.

9. Maksimalkan Internal Link, Selain backlink (external link), internal link juga memegang peranan penting dalam optimasi SEO. Internal link adalah link dari satu halaman ke halaman lain dalam satu website yang sama. Internal link membantu mesin pencari memahami konteks dan hubungan antara halaman di website. Google mengutamakan website yang kontennya saling berhubungan dan bisa menunjukkan hubungan antar konten itu melalui internal link. Internal link secara tidak langsung juga membantu meningkatkan waktu yang dihabiskan pengunjung di website/blog yang telah dibuat. Dengan adanya internal link, pengunjung akan lebih mudah berpindah ke halaman lain dalam website untuk membaca konten yang berhubungan dengan konten sebelumnya. Semakin banyak internal link yang pengunjung klik, semakin banyak halaman yang mereka kunjungi dalam website bisnis yang dibuat.

10. Guest Post, Guest post adalah menulis artikel bukan untuk diterbitkan di blog sendiri, melainkan di blog/website orang lain. Di artikel tersebut terdapat link yang mengarah ke blog/website yang dimiliki perusahaan. Metode ini cukup efektif untuk mendapatkan backlink berkualitas. Dalam bisnis online tentu keberadaan pelanggan menjadi hal yang penting. Tidak 象 https://mahesacenter.org/

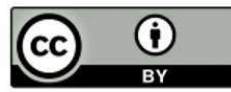


hanya pelanggan yang berada di sekitar saja namun pelanggan dari daerah atau lokasi lain akan memberikan peluang yang besar pula untuk meningkatkan pemasaran website atau produk. Dengan menggunakan SEM akan lebih meningkatkan trafik pelanggan dari lingkungan geografis yang lebih luas.

Menggunakan SEM sebagai sarana promosi akan memberikan keleluasaan untuk mengontrol baik dari biaya, timeline serta hasil yang ingin dicapai. Kontrol ini juga termasuk pada keyword serta pemilihan jenis iklan yang sesuai dengan website atau produk yang akan dipromosikan. SEM menargetkan pemasaran pada pengunjung yang relevan dengan website atau produk yang dipromosikan. Hal itu akan membuat tingkat konversi search marketing akan meningkat pula.

Search Engine Marketing menggunakan iklan berupa link yang jika di klik akan langsung menuju ke website produk yang dipromosikan. Tentu saja hal ini akan mengeluarkan biaya untuk membeli iklan tersebut. Namun sampai saat ini SEM masih merupakan promosi iklan berbayar yang paling populer digunakan karena hanya mengeluarkan biaya yang ringan atau lebih sedikit dari sistem promosi berbayar lainnya.

\section{SIMPULAN}

Email marketing adalah cara yang paling efektif untuk membangun koneksi dengan calon pelanggan dan mengarahkan mereka menjadi pelanggan setia. Email marketing juga cara yang bersifat personal untuk berkomunikasi dengan pelanggan. Tidak sembarang orang atau perusahaan mendapat suatu alamat email. Jika mendapatkan alamat email pun mereka mengirim sebuah pesan berdasarkan izin dari pengguna email yang tertuju. Pemasaran email bekerja dengan sebaik-baiknya bila dipersonalisasi dengan lebih optimal. Email dapat disesuaikan dengan tindakan pelanggan sehingga setiap komunikasi bisa relevan dengan minat mereka. Email dapat mencakup topik seperti perubahan di perusahaan, kesuksesan perusahaan, permintaan masukan atau saran dari pelanggan dan masih banyak topik lainnya yang dapat meningkatkan keterlibatan pelanggan (customer engangement). Jika engangement perusahaan dengan customer meningkat, kemungkinan besar conversion rate meningkat juga.

\section{DAFTAR PUSTAKA}

Andrianto, S., \& Wijoyo, H. (2020). Rancang Bangun Sistem Informasi Siswa Berbasis Web di Sekolah Minggu Buddha Vihara Dharmaloka Pekanbaru. TIN: Terapan Informatika Nusantara, 1(2), 83-90.

Cahyono, Y., Purwanto, A., Sukanta, F. N. A., Fitriaty, H. W., Sihotang, M., \& Sugianto, A. (2020). Impact Of Service Quality, University Image And Students Satisfaction Towards Studentloyalty: Evidence From Indonesian Private Universities. Journal of Critical Reviews, 7(19), 3916-3924.

Haudi, H. W., \& Cahyono, Y. (2020). Analysis Of Most Influential Factors To Attract Foreign Direct Investment. Journal of Critical Reviews, 7(13), 4128-4135.

Haudi, H. W., \& Cahyono, Y. (2020). Effect Of Product Innovation And Marketing Strategy On Consumer Purchase Decisions In Indonesia's Lightweight Roof Steel Industry. Journal of Critical Reviews, 7(13), 4147-4155.

Musnaini, Wijoyo, H., Indrawan, I., \& Syahtriatna. (2020). DIGIPRENEURSHIP (KEWIRAUSAHAAN DIGITAL).

Sulistyandari, Widiastuti, E., \& Indriati, S. (2017). Kemasan produk sebagai strategi pemasaran kerupuk rambak "mirasa" di desa dukuhturi, kec. Bumiayu, kab. Brebes. Adimas : Jurnal Pengabdian Kepada Masyarakat, 1(2), 1. https://doi.org/10.24269/adi.v1i2.597

Wijoyo, H. Sistem informasi pemesanan makanan dan minuman di rumah makan putri minang jaya. Js (jurnal sekolah), 3(3), 214-224.

Wijoyo, H., Indrawan, I., \& Firmansyah. (2020). Kewirausahaan berbasis teknologi (teknopreneurship). Cv. Pena persada.

Wijoyo, H., Sunarsi, D., Indrawan, I., \& Cahyono, Y. (2020). Manajemen Pemasaran Di Era Globalisasi (M. Prof. Dr. Ir. H. Anoesyirwan Moeins, MSi. (ed.)). CV. PENA PERSADA.

Wijoyo, H. Perancangan Sistem Informasi Administrasi pada Quality Fresh Laundry Pekanbaru. JS: Jurnal Sekolah, 4(1), 27-32.

Wijoyo, H., \& Marpaung, S. L. (2020). The Influence of Quality Information and Reputation Of TIX ID Application Toward the Interest of Purchase Tickets Online in XXI Cinema Ciputra Seraya Mall Pekanbaru City. Jurnal Suluh Pendidikan, 8(2), 9-21. https://doi.org/10.36655/jsp.v8i2.275

ww https://mahesacenter.org/

(v)ebmsjournal@gmail.com

45

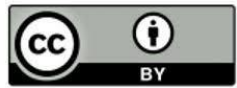

This work is licensed under a Creative Commons Attribution 4.0. 
Yahya, M., \& Wijoyo, H. (2020). Developing School Information Program: Integrated Management System based on Character Value at SMP Negeri 9 Tapung. International Journal of Asian Education, 1(3), 179-186. 